\title{
A State of Art Literature Survey on Different Fault \& Condition Monitoring of HVDC System Using Neuro-Fuzzy S \& ANN Approach
}

\author{
Nikita Rathore ${ }^{1}$, Manish Shah ${ }^{2}$ MIEEE, MIE, MISLE \\ M Tech Scholar, Dept of Electrical Engineering, VITS Indore, India ${ }^{1}$ \\ Asst. Prof. Dept of Electrical Engineering, VITS Indore, India ${ }^{2}$
}

\begin{abstract}
This paper presents an accurate system for condition monitoring and fault identification of HVDC converter using ANFIS and ANN. Here integrated fault identifier is used instead of neural network control. An integrated fault identifier is effective for complete bridge converter. Fault identification methods are applicable in both inversion and rectification modes. ANFIS based current controller is developed for a HVDC system. ANFIS based control can be easily combined with the fault identifier to form integrated system which can improve the dynamic response of HVDC system.
\end{abstract}

Keywords: ANFIS, ANN, HVDC converter, fault diagnosis, HVDC control.

\section{INTRODUCTION}

In the recent years with growing industrial applications in the field of artificial intelligence, ANFIS and ANN are used to improve the dynamic response of HVDC system and to improve its reliability. The past two decades has revealed great advances in the application of artificial intelligence to power system [1, 2]. A trend that is growing in visibility relates to the use of fuzzy inference system with neural network (ANFIS) instead of only fuzzy or neural networking. Number of papers are available that deal with the application of ANFIS in the area of power system. In [3] a hybrid scheme using Fourier linear combiner and fuzzy expert system for the classification of transient disturbance waveform is presented. An integrated fuzzy expert system is presented in [3] to diagnose different fault in regional transmission network and substation. In [6] different methods based on artificial neural network (ANN) to identify various faults that may occur in HVDC converter are presented.

Wavelet based fuzzy reasoning approach to the power quality disturbance recognition is presented in [7].

Fuzzy inference systems and neural networks are complementary technologies in the design of adaptive intelligence system. Artificial Neural Network (ANN) learns from scratch by adjusting the interconnections between layers. Fuzzy Inference System (FIS) is a popular computing framework based on the concept of fuzzy set theory, fuzzy if-then rules, and fuzzy reasoning.

A neuro-fuzzy system is simply a fuzzy inference system trained by a neural network- learning algorithm. The learning mechanism fine-tunes the underlying fuzzy inference system.

Artificial Neural Network (ANN) has capability to map complex and highly nonlinear input-output behaviour.
But many methods are incomplete to detect faults in HVDC converter using the concept of signature analysis.

The integrated neuro-fuzzy system combines advantages of both ANN and FIS. Application of both technologies is categorized into following four cases:

1. NN's used to automate the task of designing and fine tuning the membership functions of fuzzy systems.

2. Both fuzzy inference and neural network learning capabilities acting separately.

3. NN's work as correcting mechanisms for fuzzy systems. 4. NN's customizes the standard system according to each user's preferences

And individual needs.

The integrated neuro-fuzzy system combines advantages of ANN and FIS. Some of the major works in the area of neuro-fuzzy system are GARIC, FALCON, ANFIS, EfuNN, dmEEuNN, etc.

The HVDC system traditionally uses PI controllers to control the DC current thereby keeping the power (current) order at the required level. Although these controllers undoubtedly are robust and are operating satisfactorily for many years, they are prone to changes in system parameters, delays or other non-linearities in the system and suffer from some limitations. This paper describes fault identification and protection of a HVDC converter using ANFIS based fault identifier (ANFLBI). ANNs have been extensively used for the fault diagnosis, load demand forecasting, system identification, state estimation etc., in power systems. Unlike other controllers, ANFIS controller does not require a mathematical model of the system to estimate control input under disturbance conditions. Power system reliability improves when 
HVDC converter faults are detected and eliminated before they deteriorate to a severe state.

The paper is organized as follows: 1) HVDC system under study is defined. 2) Classification of faults. 3) Introduction on ANFIS system. 4) Application of ANFIS for HVDC control is given. 5) Use of ANFIS for fault identification. 6) Introduction to ANN and its disadvantages. 7) Conclusions and work to be done in future is suggested.

\section{HVDC SYSTEM}

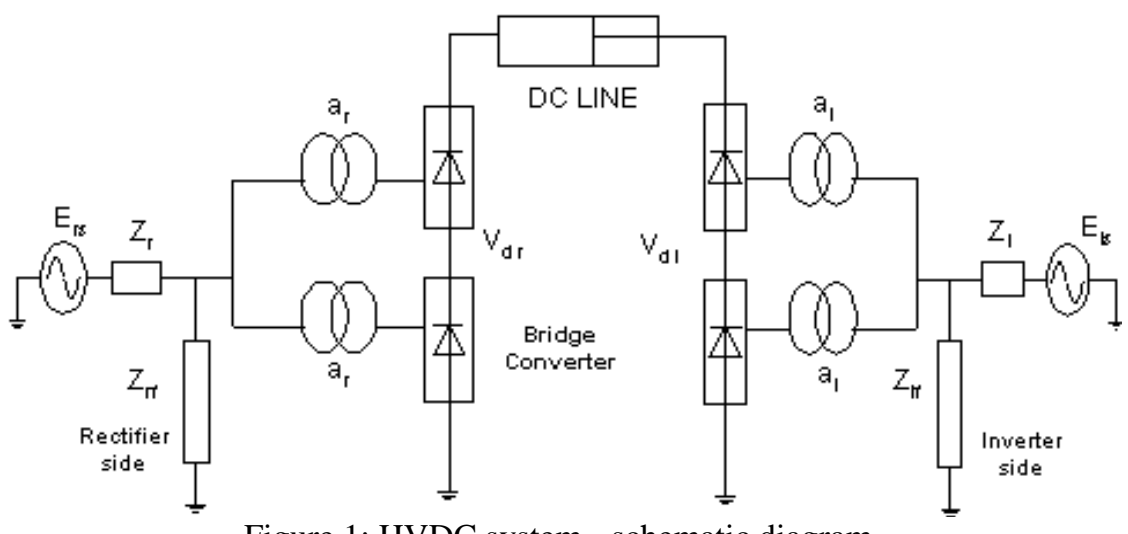

Figure 1: HVDC system - schematic diagram.

\section{HVDC system model}

The HVDC system used here as a test system is a 12pulse, 1000 MW (500 kV-2kA) 50/60 Hz HVDC transmission system (S. Casoria; Hydro-Quebec (IREQ). A $1000 \mathrm{MW}(500 \mathrm{kV}, 2 \mathrm{kA})$ DC interconnection is used to transmit power from the $500 \mathrm{kV}, 5000 \mathrm{mVA}, 60 \mathrm{~Hz}$ network to $345 \mathrm{kV}, 10000 \mathrm{mVA}, 50 \mathrm{~Hz}$ network. The converters are interconnected through a $300 \mathrm{~km}$ distributed parameter line and smoothing reactor of $0.5 \mathrm{H}$. The reactive power required by the converters is provided by a set of filters (Capacitor bank plus 11th, 13th and high pass filters; total $600 \mathrm{MVAR}$ on each side). Fig. 1 shows a typical HVDC system using 6 pulse Graetz's Bridge configuration. Two 6-pulse bridges in series constitute a 12-pulse converter.

\section{Classification of faults}

The faults that occur in an HVDC line are mainly of two types. These faults [5] can be identified easily by analyzing the current data. Current at the two terminals A $\&$ B of the DC transmission line are different in each type of fault.

There are two types of fault:

1. Open Circuit Fault: In this fault the line breaks and an open circuit fault occurs. Both terminal currents are zero.

2. Pole to Ground Fault: In this fault the values of terminal currents are not equal to zero. The value of terminal current $I_{a}$ will be greater than $I_{b}$

\section{ADAPTIVE NEURO-FUZZY INFERENCE SYSTEM (ANFIS)}

Fuzzy systems are generally used in cases when it is impossible or too difficult to define crisp rules that would describe the considered process or system, which is being controlled by a fuzzy control system. Thus, one of the advantages of fuzzy systems is that they allow describing fuzzy rules, which fit the description of real-world processes to a greater extent. Another advantage of fuzzy systems is their interpretability; it means that it is possible to explain why a particular value appeared at the output of a fuzzy system. In turn, some of the main disadvantages of fuzzy systems are that expert input or instructions are needed in order to define fuzzy rules, and that the process of tuning of the fuzzy system parameters (e.g., parameters of the membership functions) often requires a relatively long time, especially if there is a high number of fuzzy rules in the system. Both these disadvantages are related to the fact that it is not possible to train fuzzy systems. A diametrically opposite situation can be observed in the field of neural networks. User can train neural networks, but it is extremely difficult to use a priori knowledge about the considered system and it is almost impossible to explain the behaviour of the neural system in a particular situation.

In order to compensate the disadvantages of one system with the advantages of another system, several researchers tried to combine fuzzy systems with neural networks. A hybrid system named ANFIS (Adaptive-Network- Based Fuzzy Inference System or Adaptive Neuro-Fuzzy Inference System) has been proposed in [10]. ANFIS is the fuzzy-logic based concept that grasps the learning abilities of ANN to enhance the intelligent system's performance using a priori knowledge.

Using a given input/output data set, ANFIS constructs a fuzzy inference system (FIS) whose membership function parameters are tuned (adjusted) using either a back propagation algorithm alone, or in combination with a least squares type of method. This allows your fuzzy systems to learn from the data they are modelling.

These techniques provide a method for the fuzzy modelling procedure to learn information about a data set, 
in order to compute the membership function parameters To use ANFIS for classification problem, the designer that best allow the associated fuzzy inference system to needs to perform the following steps:

track the given input/output data. This learning method 1. Design a Sugeno FIS appropriate for the classification works similarly to that of neural networks.

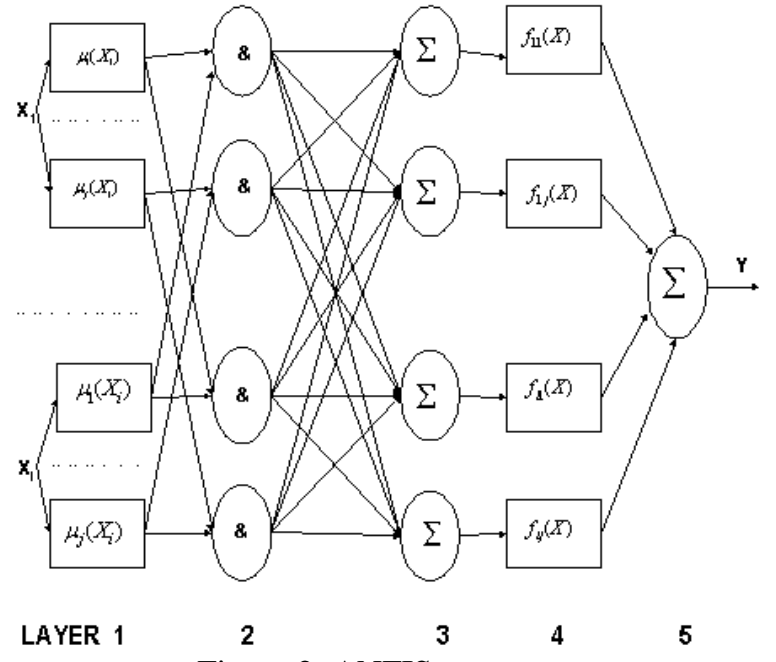

Figure 2: ANFIS structure.

Fig. 2 shows the basic structure of the ANFIS algorithm for a first order Sugeno-style fuzzy system. It is worth noting that the Layer-1 consists of membership functions described by the generalized bell function

$$
\mu(X)=(1+((X-c) / a) 2 b)-1
$$

Where $\mathrm{a}, \mathrm{b}$ and $\mathrm{c}$ are adaptable parameters.

Layer-2 implements the fuzzy AND operator, while Layer- 3 acts to scale the firing strengths. The output of the Layer-4 is comprised of a linear combination of the inputs multiplied by the normalized firing strength $\mathrm{w}$ :

$$
\mathrm{Y}=\mathrm{w}(\mathrm{pX}+\mathrm{r})(2)
$$

where $\mathrm{p}$ and $\mathrm{r}$ are adaptable parameters. Layer-5 is a simple summation of the outputs of Layer-4. The adjustment of modifiable parameters is a two-step process. First, information is propagated forward in the network until Layer-4 where the parameters are identified by a least-squares estimator. Then the parameters in Layer-2 are modified using gradient descent. The only user specified information is the number of membership functions in the universe of discourse for each input and output as training information.

ANFIS uses back propagation learning to learn the parameters related to membership functions and least mean square estimation to determine the consequent parameters. Every step in the learning procedure includes two parts. The input patterns are propagated and the optimal consequent parameters are estimated by an iterative least mean square procedure. The premise parameters are assumed fixed for the current cycle through the training set. The pattern is propagated again, and in this epoch, back propagation is used to modify the premise parameters while the consequent parameters remain fixed. problem.

2. Hands optimize the FIS, given actual input classification data.

3. Set up training and testing matrices. The training and testing matrices will be composed of inputs and the desired classification corresponding to those inputs.

4. Run the ANFIS algorithm on the training data.

5. Test the results using the testing data.

ANFIS uses either back propagation or a combination of least squares estimation and back propagation for membership function parameter estimation. The next section describes application of ANFIS for HVDC control.

\section{ANFIS BASED HVDC CONTROL}

In this paper ANFIS based current controller is presented which preserves all the advantages of fuzzy systems and uses neural network at the front end to optimize performance of the overall system. To train ANFIS based control, training data is obtained from HVDC system, which is equipped with a conventional PI based constant current controller (see Fig. 3). ANFIS is trained using 70\% of the data while $30 \%$ is used for testing and validation.

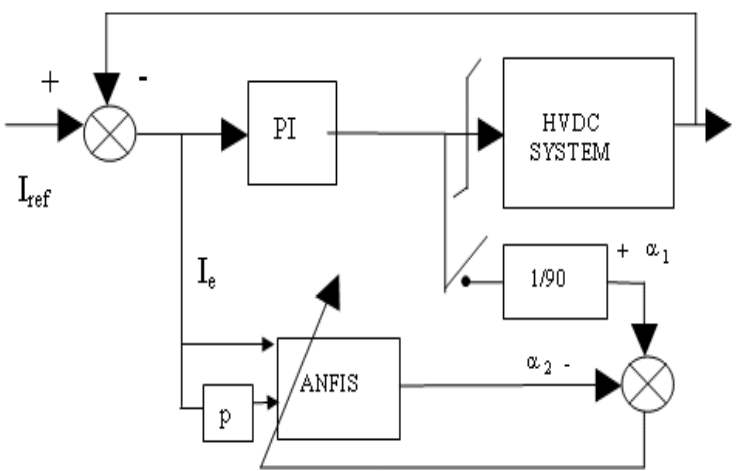

Figure 3: Off-line trained ANFIS control.

Response of the designed ANFIS current controller is shown in Fig. 3 for variation in DC reference current $\left(\mathrm{Id}_{\mathrm{ref}}\right)$. Performance of HVDC system improves if faults within converter are detected and fault development control initiates some corrective action. The next section deals with use of ANFIS for fault identification.

\section{ANFIS BASED FAULT IDENTIFICATION}

As the data in HVDC system are highly uncertain and the power disturbance monitoring is a pattern classification problem, therefore ANFIS based expert system is adopted for designing fault identifier.

The existing method available for converter fault identification may give a very quick indication of the converter fault with the assumption that the overlap angle $\mu$ is limited up to 60 degrees. But the accuracy of the 


\section{International Journal of Innovative Research in Electrical, Electronics, Instrumentation and Control Engineering \\ ISO 3297:2007 Certified}

Vol. 5, Issue 2, February 2017

identifier totally relies on the proper selection of the delay time, i.e. the delay time exceeding the expected overlap angle $\mu$ may give false indication of fire-through and false indication of commutation failure if the delay angle is not sufficient. To overcome this problem, fault identifiers are designed using artificial neural network to detect commutation failure, fire through, and other faults within the converter bridge [8], in which three different methods are presented to detect various faults in HVDC converter using the artificial neural network and comparison is made between different methods. But in these methods, one identifier per valve is required, i.e. six identifies are required for a Graetz bridge converter.

To eliminate this problem, work is going on for designing an integrated type of fault identifier based on ANFIS.

\section{INTRODUCTION TO ANN}

ANNs have been extensively used for the fault diagnosis, load demand forecasting, system identification, state estimation etc., in power systems. The increasing use of AI paradigms (i.e. based on ANNs, Fuzzy logic, Expert Systems etc.) in recent years in the area of HVDC systems is indicative of the three promising features associated with these new techniques, an investigation into the architectural and functional aspects of an online ANN based current controller for an HVDC (plant) system is considered. Artificial Neural Network (ANN) has capability to map complex and highly nonlinear inputoutput behaviour.

But many methods are incomplete to detect faults in HVDC converter using the concept of signature analysis. Limitation of the existing method is examined and three new ANN based methods are proposed [7] to provide discrete and unambiguous indication of converter fault. Proposed identifiers are very attractive for real time implementation because of their simple architecture. Comparison between different methods is also made. High Voltage Direct Current (HVDC) transmission plays an important role in today's electrical power transmission systems. The DC voltage in conjunction with fast acting power electronic devices in an HVDC system makes it the most reliable method for power transmission over long distances, and power injection into load buses without much concern about system stability and dynamics. HVDC systems have been in service for over half a century, and their performance is greatly affected by the control methods used.

\section{CONCLUSION}

Comparison of neural network based methods and ANFIS based current controller for HVDC system is done. For better reliability of HVDC system integrated type fault identifier based on ANFIS will be designed in future.

Instead of using separate fault identifier for each valve, an integrated fault identifier is developed which is effective for the complete bridge converter. Fault identifier, which is developed, is able to provide discrete and unambiguous indication of converter faults such as commutation failure and arc through/fire through of a valve within the converter. Fault identifiers are tested for HVDC with strong and weak ac side. Fault identification methods are applicable in both inversion and rectification mode.

ANFIS based control can be easily combined with the ANFIS based fault identifier to form integrated system, which can improve dynamic response of the HVDC system.

\section{REFERENCES}

[1] Routray, P.K. Dash, and S.K. Panda, IEEE Trans. Power Electronics 11, 669 (1996).

[2] Daneshpooy, A.M. Gole, D.G. Chapman, and J.B. Davies, IEEE Trans. Power Delivery 12, 1690 (1997).

[3] H.-J. Lee, D.-Y. Park, B.-S. Ahn, Y.-M Park, J.-K. Park, and S.S. Venkata, IEEE Trans. Power Delivery 15, 833 (2000).

[4] Huisheng Wang and W.W.L.Keerthipala, "Fuzzy-Neuro Approach to Fault Classification for Transmission Line Protection," IEEE Transaction on power Delivery, Vol: 13, No.4, October, 1998, pp:1093-1104.

[5] Khushboo Nagar, Manish Shah, International Journal of Innovative Research in Engineering \& Management (IJIREM) ISSN: 23500557, Volume-3, Issue-6, November-2016, Copyright (C) 2016. Innovative Resea

[6] N. Bawane and A.G. Kothari, J. of Circuits, Systems, and Computers 13, 813 (2004).

[7] P.K. Dash, S. Mishra, M.M. Salama, and A.C. Liew, IEEE Trans. Power Delivery 15, 472 (2000).

[8] T.X. Zhu and S.K. Tso, IEEE Trans. Power Delivery 19, 1928 (2004)

[9] Sourabh Mehto, Rahul Agarwal, Manish Shah, "A Comparative Study Based on PI and Fuzzy Control of Inverter fed Induction Motor Drive", International Journal of Research (IJR) Vol-2, Issue2 February 2015 ISSN 2348-6848, pp.75-79.

[10] Juhi Nagpal, Rahul Agarwal \& Manish Shah, "A Comparative Study on Different Speed Control Methods of D.C. Drives for Electric Vehicle", International Journal of Research (IJR) e-ISSN: 2348-6848, p- ISSN: 2348-795X Volume 2, Issue 07, July 2015, pp. 1-6.

[11] Khushboo Hardia, Neha Maithil \& Manish Shah, "Particle Swarm Optimization Applied To Economic Load Dispatch Problem", International Journal of Research (IJR) e-ISSN: 2348-6848, pISSN: 2348-795X Volume 2, Issue 09, September 2015, pp. 834-843.

12] Jyoti verma, Manish Shah, "Simulation and Analysis of H-bridge Cascade Multi level Inverter Fed Induction Motor Drive for Industrial Applications", International Journal of Innovative Research In Electrical, Electronics, Instrumentation And Control Engineering Vol. 4, Issue 3, March 2016, pp. 17-19.

[13] Manish Shah, Rahul Agrawal, "A Review On Classical And Modern Techniques with Decision Making Tools For Load Forecasting", International Journal of Emerging Trends in Engineering and Development Issue 3, Vol.6 (November 2013), pp. 174-184.

[14] Ritu Bhateja, Manish Shah, "A Proposed Method for Smooth Speed Control of Indirect Vector Control Inverter-Fed Induction Motor Drive using Boost Converter Topology",

[15] International Journal of Emerging Trends in Engineering and Development Issue 6, Vol. 5 (September 2016), pp. 1-10.

[16] Sudeep Mohaney, Sourabh Mehto, Manish Shah, "Modeling and Optimization of Elevator Group Control System for High Rise Commercial Building", IEEE International Conference on Computer, Communication and Control (IC4-2015).

[17] Sudeep Mohaney, Manish Shah, "Emerging Trends in Vertical Elevating System", International Journal of Engineering and Management Research Vol.-5, Issue-1, February-2015, pp. 51-56.

[18] Khushboo Nagar, Manish Shah, "A Review on Different ANN Based Fault Detection Techniques for HVDC Systems", International Journal of Innovative Research in Engineering \& Management (IJIREM), Issue-6, 2016. 